DOE/ER/45314-6

\title{
PLASMA, PHOTON, AND BEAM SYNTHESIS OF DIAMOND FILMS AND MULTILAYERED STRUCTURES
}

\author{
Final Report
}

for the period July 1996 - December 1998

\author{
R.P.H. Chang
}

Materials Science \& Engineering Dept.

Northwestern University

Evanston, IL 60208

January 1999

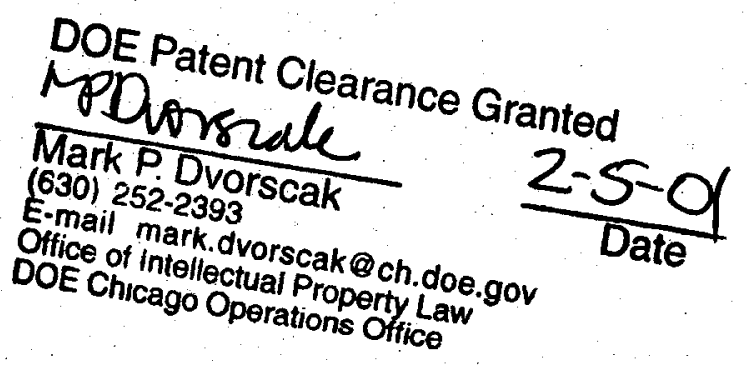

Prepared for

THE US. DEPARTMENT OF ENERGY

AGREEMENT NO. DE FG02-87ER45314 


\section{DISCLAIMER}

This report was prepared as an account of work sponsored by an agency of the United States Government. Neither the United States Government nor any agency thereof, nor any of their employees, makes any warranty, express or implied, or assumes any legal liability or responsibility for the accuracy, completeness, or usefulness of any information, apparatus, product, or process disclosed, or represents that its use would not infringe privately. owned rights. Reference herein to any specific commercial product, process, or service by trade name, trademark, manufacturer, or otherwise does not necessarily constitute or imply its endorsement, recommendation, or favoring by the United States Government or any agency thereof. The views and opinions of authors expressed herein do not necessarily state or reflect those of the United States Government or any agency thereof. 


\section{DISCLAIMER}

Portions of this document may be illegible in electronic image products. Images are produced from the best available original document. 


\section{Abstract}

The DOE has been supporting professor Chang and his students in the area of plasma and photon synthesis of diamond-like and ceramic films with varying complexity during the past three years. We have made substantial contribution to the field during this period of time. Some of the important questions have been addressed, and they include: a. How does the energy (wavelength) of the laser change the composition and energy distribution of the ablated species? b. How do surface mobility and the intensity of the plasma plume affect crystal nucleation and growth? c. How can one manipulate the system parameters during film growth to achieve special properties for unique applications?

In the area of photon synthesis, we have shown that amorphous diamond films can have properties very similar to polycrystalline diamond films and yet they may have wider applications in such areas as coating and electronics. For example, we have shown that these films can be used to protect plastics such as polycarbonate surfaces. During the course of our amorphous diamond films research, we have also identified important parameters which alter the film properties. Higher photon energy and laser power density contribute to higher percentage of carbon ion density and energy in the plasma plume. This in turn proves films with higher percentage of diamond like $\mathrm{sp}^{3}$ bonds and thus diamond like properties of the films. Lower photon energies and collision of the plasma plume with background gas will produce films which are rich in graphitic properties.

In the area of oxide film growth, we have found, in general, that better crystalline films can be grown by laser ablation at much lower substrate temperatures than by chemical vapor deposition process. This is due to the fact that in laser ablation the depositing species have more kinetic energies and the whole process involves rapid solidification. By using optical emission spectroscopy, we have learned how to adjust the deposition parameters to control film properties such as grain size and crystal orientations. These control capabilities have allowed us to grow oxide films with unique properties, such as high optical nonlinearity. In addition, we have been able to grow films with special crystalline orientations to serve as templates for chemical vapor deposition processes. 


\section{Results}

A summary of the significant contributions are given below, while copies of reprints and preprints are included in the appendix.

\subsection{Diamond-like films}

Using an ArF excimer laser we have successfully deposited at room temperature "hydrogen free" diamond-like carbon films with over $95 \% \mathrm{sp}^{3}$ or diamond like bonds. These films have a hardness of $38 \mathrm{GPa}$, an optical energy band gap of $2.6 \mathrm{eV}$, and an excellent thermal stability [1/4]. However, if we change the deposition parameters, such as substrate temperature, laser wavelength, or ambient gas in the processing chamber we are able to change the film phase composition, i.e. bond structure ratios of $\mathrm{sp}^{3} / \mathrm{sp}^{2}$ in the film. These controls are found to be extremely important for applications in the area of hard coating and electron field emission.

In the area of applications, we have succeeded in depositing amorphous diamond films on polycarbonate by using oxygen plasma pretreatment to enhance the surface chemical bonding and increase the effective surface area. These thin films provided a hardness of about $5 \mathrm{Gpa}$, while the polycarbonate has a hardness of only $0.2 \mathrm{GPa}$. In addition to nano-hardness measurements, the surface morphology has also been studied by atomic force microscopy. (For further details, please see appendix 1)

\subsection{Optical emission studies of laser generated carbon plasma}

To understand the carbon film properties deposited by laser ablation, we spent time to understand the nature of the plasma plume that is produced by our ArF laser. Using optical emission spectroscopy (OES), we have studied the properties of the carbon plasma plume under different laser intensities. We found that there is a correlation between the film properties and the concentration of carbon atoms and ions in the plasma plume. The use of time resolved technique to follow the evolution of the different plasma species will be pursuit in the near future. . Details of our OES studies are given in appendix 2.

1.3 Morphological control and growth of ultra-flat polycrystalline diamond films with application to tribology

We have succeeded in growing ultra-flat polycrystalline diamond films by carefully control the crystal morphology in time. Optimum conditions have achieved for the growth of smooth homoepitaxial diamond films. High quality (100) films are dependent on optimizing the layers by layer growth on the (100) surface. Using these same deposition conditions, the morphology of heteroepitaxial polycrystalline diamond films show unique octahedral shaped facets with a $\langle 100\rangle$ fiber texture. Nitrogen addition enhanced the rate at which octahedral crystals become more normal to the substrate surface. By subjecting the film to high temperature/low percentage of methane, growth velocity is shifted from $\langle 100\rangle$ direction to the $<111>$ direction leading to a flat (100) faceted polycrystalline film suitable for optical and tribological applications. (Please see appendix $3 / 4$ for details)

\subsection{Properties of laser ablated $\mathrm{SiC}$ films}

Using our laser ablation system we have studied in detail the process of depositing $\mathrm{SiC}$ film both in an ultra-high vacuum ambient and in a nitrogen gas environment. The 
microhardness and film stress have been studied. It was found that the film crystallinity and phase are very sensitive to the deposition parameters. For example, an addition of nitrogen gas during laser ablation can easily convert $\mathrm{SiC}$ films into mostly $\mathrm{SiO}_{2}$ films if the vacuum chamber has a base pressure higher than $10^{-6}$ torr due to the presence of water vapor. These are important issues to control the film properties for specific applications. In related experiments we have discovered that by adjusting the film properties we are able to observe very high second harmonic generation with coefficients 35 time that of quartz. This number is $1 / 3$ of the theoretical value for single crystal SiC. (For further details, please see appendix 4/5)

1.5 Epitaxial growth of yttria-stabilized zirconia on $(0001) \mathrm{Al}_{2} \mathrm{O}_{3}$ using pulsed laser deposition

We are studying the pulsed laser deposition of yttria-stabilized zirconia (YSZ) films on (0001) $\mathrm{Al}_{2} \mathrm{O}_{3}$ as a function of oxygen partial pressure. We observe that at low ( 0.05 Torr) oxygen pressure the preferred growth orientation is (111), while at high (0.3 Torr) the growth of (001) YSZ is favorable. Thus, a simple two-step process has been developed to grow (001) epitaxial $\mathrm{YSZ}$ on (0001) $\mathrm{Al}_{2} \mathrm{O}_{3}$ by manipulating the laser-induced plasma. (Please see appendix 5 for details)

1.6 Crystalline properties of heteroepitaxial $\mathrm{ZnS}$ films on (0001) sapphire by pulsed laser deposition

We have grown hexagonal $\mathrm{ZnS}$ films on (0001) sapphire substrates by laser ablation. High quality films can be prepared at growth temperatures of $450-550 \mathrm{C}$ with rocking curve FWHM of (0001) ZnS as narrow as 0.08 degree. High resolution cross-section transmission electron microscopic (HRTEM) analysis of the films deposited at 500C shows cubic $\mathrm{ZnS}$ grains inhabit near interface and therefore the interfacial region is highly defective. However, the surface region, above a critical thickness of about $5 \mathrm{~nm}$, consists of pure hexagonal structure with a very high level of crystallinity. Doping of the $\mathrm{ZnS}$ with oxygen can be achieved by introducing molecular oxygen during deposition. X-ray diffraction and compositional analysis show that films with good crystal structure and uniform doping level can be prepared at $0.01 \mathrm{mT}$ Trr of oxygen. An increase of oxygen pressure to $0.1 \mathrm{~m}$ Torr causes the films to become polycrystalline. (See appendix 6 for details)

Three major areas of research on diamond, diamond-like, and nanophase $\mathrm{SiC}$ films have been carried out during the past year. Polycrystalline diamond films with any orientation and surface morphology can now be grown in a controlled manner by carefully adjusting the deposition conditions such as gas mixtures. By careful preparation of the polycarbonate (plastic) surface, we have succeeded in depositing diamond-like films on these surfaces. In addition, we have studied the properties of $\mathrm{SiC}$ films deposited by laser ablation.

\section{Status of Researchers}

Postdoctoral researcher, Dr. Hock-Chun Ong left Northwestern to teach at Hong Kong City University, November 1998.

Visiting Scholar from China, Dr. Jayin Dai, left the university for a position at the National University of Singapore, September 1998. 


\section{Publications/Presentations Supported by This Grant:}

1. "The Effect of Laser Intensity on the Properties of Carbon Plasmas and Deposited Films," H.C. Ong and R.P.H. Chang, Physical Review B, 55, 13,213 (1997).

2. "Structural Characterization of Pulsed Laser Deposited Hydroxyapatite Film on Titanium Substrate," Wang, C.K., J.H. Lin, C.P. Ju, H.H. Ong, and R.P.H. Chang, Biomaterials, 18, 1331 (1997).

3. "Epitaxial Growth of Yttria-Stabilized Zirconia on (0001) $\mathrm{Al}_{2} \mathrm{O}_{3}$ Using Pulsed Laser Deposition," H.C. Ong, J.-Y. Dai, R.P.H. Chang, Appl. Phys. Letts, (1998).

4. "Crystalline Properties of Heteroepitaxial ZnS Films on (0001) Sapphire by Using Pulsed Laser Deposition," H.C. Ong, J.-Y. Dai, R.P.H. Chang, Appl. Phys. Letts, (1998).

5. "Stability of Bilayer Films of YBCO and YSZ Grown on LAO by Chemical Vapor Deposition," F.H. Kaatz, P.R. Markworth, J.Y. Dai, D.B. Buchholz, X. Liu, M. Chudzik, J.A. Belot, C.R. Kannewurf, T.J. Marks, and R.P.H. Chang, Advanced Materials, 4, 99 (1998).

6. "Determination of the Optical Constants of Zinc Oxide Thin Films by Spectroscopic Ellipsometry," P.L. Washington, H.C. Ong, J.Y. Dai, and R.P.H. Chang. Appl. Phys. Letts, $72,3261(1998)$.

7. "Charge Transport, Optical Transparency, Microstructure, and Processing Relationships in Transport Conductive Indium-Zinc Oxide Films Grown by Low-Pressure Metal-Organic Chemical Vapor Deposition," Anchuan Wang, Jiyan Dai, Jizhi Cheng, Michael P. Chudzik, Tobin J. Marks, Robert P.H. Chang and Carl R. Kannewurf, Appl. Phys. Lett, 73, 327 (1998).

8. "Nanocrystalline Diamond Films from Argon Microwave Plasmas: Phase Purity, Microstructure, Growth Mechanism, and Applications," D.M. Gruen, A.R. Krauss, D. Zhou, T.G. McCauley, T.D. Corrigan, R.P.H. Chang, and G.M. Swain, Electroc. Soc. Proc., 97-25, 325 (1997).

9. "Second harmonic generation in laser ablated zinc oxide thin films," H. Cao, J.Y. Wu, H.C. Ong, J.Y. Dai, and R.P.H. Chang, Appl Phys. Lett, 73, 572 (1998).

10. "Stability of Bilayer Films of YBCO and YSZ Grown on LAO by Chemical Vapor Deposition," F.H. Kaatz, P.R. Markworth, J.Y. Dai, D.B. Buchholz, X. Liu, M. Chudzik, J.A. Belot, C.R. Kannewurf, T.J. Marks, and R.P.H. Chang, Advanced Materials, 4, 99 (1998). 
11. "Determination of the Optical Constants of Zinc Oxide Thin Films by Spectroscopic Ellipsometry," P.L. Washington, H.C. Ong, J.Y. Dai, and R.P.H. Chang. Appl. Phys. Lett, 72, 3261 (1998).

12. "Atomic Layer Controlled Growth of Transparent Conducting $\mathrm{ZnO}$ on Plastic Substrates," A.W. Ott and R.P.H. Chang, in press Mater. Chem. \& Phys. (1998).

13. "Ultraviolet lasing in resonators formed by scattering in semiconductor polycrystalline films," H. Cao, Y.G. Zhao, H.C. Ong, Q. Wang and R.P.H. Chang, Appl. Phys. Lett, 73, (1998).

B. Oral Presentations:

1. "Epitaxial Growth of Yttria-Stabilized Zirconia (YSZ) on (0001) Al2O3 Using Pulsed Laser Depostion," J.Y. Dai, H.C. Ong, and R.P.H. Chang, MRS Fall Meeting, Nov. 30Dec. 5, 1997, Boston, MA.

2. "Epitaxial Growth of Hexagonal $\mathrm{ZnBeO} / \mathrm{ZnO}$ Quantum Heterostructures Using Pulsed Laser Deposition, H.C. Ong, H. Cao, X. Liu, J.Y. Dai, and R.P.H. Chang, MRS Spring Meeting, April 1998, San Francisco, CA. 